\title{
Creating WWW-based Soap Operas for Learning English
} Ken Keobke City University of Hong Kong

\section{Introduction}

"IT]he successful use of the IWorld Wide Web] requires a rethinking of pedagogy and experimentation with literary forms."
The World Wide Web (WWW) offers new ways to disseminate information and conduct teaching and learning. But the successful use of the medium requires a rethinking of pedagogy and experimentation with literary forms. This article shows how one novel form, the virtual soap opera, can be used to encourage learning.

Mumford (1995) defines the term soap opera as "...a continuing fictional dramatic television program, presented in multiple serial installments each week, through a narrative composed of interlocking story lines that focus on the relationships within a specific community of characters" (Mumford 18). Although the example in this article, The Secret Diaries of Lotus and Rose (http://www.cityu.edu.hk/ls/ lotus\&rose) uses the medium of the WWW, it functions much the same way and takes advantage of what Modelski describes as the two most important aspects of the medium of television: intimacy and continuity. Modelski goes on to quote Horace Newcomb ("TV: the most popular art") "... because of the serial nature of the programs, television can offer us depictions of people in situations which grow and change over time, allowing for greater "...audience involvement, a sense of becoming a part of the lives and actions of the characters they see" (Modelski, 87). In Lotus and Rose, sixteen weekly episodes trace the relationship of two young Hong Kong women, Lotus and her supposed cousin, Rose as well as two young men with whom they become involved as they undertake a series of adventures local to Hong Kong and documented in their (always conflicting) diary entries.

The idea for a WWW-based soap opera is not completely new. Among the earliest and most successful was the 1995 (now-defunct) The Spot (www.thespot.com). The structure involved six friends who went through various relationships with each other and about forty less important characters, 
"In this way, the $W W W$ is very different from its television counterpart; not everyone needs to read/experience the same story, or even

follow the whole story." including pets. The Spot took advantage of the interactive elements of the WWW to solicit reader/user queries and suggestions, some of which were then used to influence subsequent episodes. The Spot also featured various bits of peripheral information which served to round out the characters as real people. These included a wealth of selfcentered and introspective comments as well as general advice, resolutions, revelations, recipes and even physical workout notes (Collins 1996). The reader did not need to go to these bits of peripheral information unless his or her interest was piqued. In this way, the $W W W$ is very different from its television counterpart; not everyone needs to read and experience the same story, or even follow the whole story. It is perfectly possible to simply read the diary entries of one or more of one's favorite characters.

In this way, Lotus and Rose has aspects of interactive fiction. Howell (1990) suggests that the goals of interactive fiction are to:

- expand the creative environment of the author;

- create a medium which encourages real participation;

- bring the readers and authors into more direct contact;

- explore the possibilities of multiple authorship and interactive story generation.

Lotus and Rose does all these, although to a lesser extent than some texts which are organized as interactive fiction in which completely random paragraphs can be arranged and rearranged to create different (oftennonsensical) perspectives. In this sense, it is more like the Japanese story Rashomon, in which several people see the same murder but come away with differentstories tempered by their own conceits and parts in the drama, an approach suggested by Stuart to avoid literalization, in which users confuse the simulation with reality, instead of one programmer's view of reality (e.g. a civil war scenario in which plantation life is idealized) (Stuart 97-98). Lotus and Rose also features levels of interpretation and supplementary material that lead readers along tangents quite distant from the core materials of the diary entries. Bolter (1991) comments on this aspect of hypertext saying "In a printed book, it would be intolerably pedantic to write footnotes to footnotes. But in the computer, writing in layers is quite natural, and reading in layers is effortless. All the individual paragraphs may be of equal importance in the whole text, which then becomes a network of interconnected writings. The network is designed by the author to be explored by the reader in precisely this peripatetic fashion" (Bolter 1991: 15). Because of the serial nature of Lotus and Rose, the content increases week to week, 
adding more materials, further creating an experience quite different from traditional text, particularly as the spatial arrangement of material may encourage learners to follow tangents exploring earlier parts of the drama which had been missed because they did not seem as relevant or interesting at the time. Bolter goes on to say that "Electronic text is the first text in which the elements of meaning, of structure, and of visual display are fundamentally unstable" (Bolter 1991: 31).

\section{Issues of Content}

Traditional soap operas generally use issues of a highly sexual nature to generate plot. Katheryn Wibel lists some of the most frequent themes of soap opera:

- the evil woman

- the great sacrifice

- the winning back of an estranged lover/spouse

- marrying her for her money, respectability, etc.

- the unwed mother

- deceptions about the paternity of children

- career vs. housewife

- the alcoholic woman (and occasionally man)

(Wibel quoted in Modelski 86)

Similarly, a description of The Spot describes its "...racy, scandalous story lines -sex, murder, and more sex" (Collins 1996: back cover notes). What differentiates Lotus and Rose from television and WWW soap operas is its focus on exploring and encouraging language learning, as well as creating a story that reflects the interests of a narrow geographic area, Hong Kong.

The user enters the story at a homepage which offers a brief description that sets up the tone of the site:

Welcome to the story of Lotus and Rose, two young women who meet in Hong Kong. Follow the mysteries and mistakes in sixteen weeks of small adventures as they explore Hong Kong, new ideas and new hearts.

The options at this point are to click buttons to go to the First Diary, The Story So Far, which summarizes previous week(s) developments, This Week which, in the case of the first episode is the same as First Diary, Who Are We, which gives brief biographies of the author, the designer and the research assistant along with hotword connections to email addresses and other sites and Teach and Learn.

The First Diary page contains the first week's diary entries of Lotus and Rose, presented side by side: 
The Secret Diary of Lotus: One

This afternoon I met the strangest person. A girl, about my age, came into Aunt Ella's wedding banquet in HongKongpark. Inoticedher talking to Granny, who doesn't usually talk to anyone. Anyway, I thought, "What'sgoingon?" and remembered Shakespeare's Romeo sneaking into the wedding banquet in disguise. Imagine my surprise: Iwent over and Granny said "Look, two beautiful flowers!"Shelaughed and then forgot what she was laughing about and started eating her cake. Granny is a bit strange. But this new girl is stranger. She said her name is Rose, which is why Granny said that thing about two flowers... Lotus and Rose. Then came the strangest part: when I asked what she was doing at the wedding banquet, she just said she was my Canadian cousin. I never knew we had any relativesin Canada.

I told her that no one in my family had ever talked about her. I didn't know what to think. She said she wasn't surprised. "No one likes to talk about me." Then she said she wished she had time to explain, but that she had to leave so I gave her my phone number. But, before she left, she gave me a mah jong tile. I was so surprised, I didn't know what to say. She told me to put it in my diary box and then, like Cinderella, she ran off.

What's a diary box? Why did she give me a mah jong tile? Did she steal it from the banquet? Why did no one tell me I had a cousin in Canada? It's all too strange, but I hope she calls me soon. Lotus
The Secret diary of Rose: One

I went to a wedding banquet this afternoon... so much happiness, but also so much sadness. I think that mothers cry at weddings because they know life is short. Like flowers, we're born, we blossom and we die. Having your children leave you for another

Lotus family must make yourealize that. I met Lotus at the wedding. She seems so lovely and smart and happy. No wonder - she has a big family and lots of friends. Life has been kind to her. Life will always be kind to her. She was surprised when I told her I was her cousin. Very surprised. I took her phone number and promised to call. I will call her. But I will make her wait a few days.

When I arrived at the wedding banquet, I took a couple of mah jong tiles off a table. I gave her one and kept one myself. Things, not words, are what hold people together and although a gift can sometimes be like a little curse. When she looks at the mah jong tile, she'll think of me. When she looks at any mah jong game, she will have a vague memory of me. And when she hears mah jong players slamming down their tiles like machine gun fire, in the back of her mind she'll remember me. Now, the next time I see her, it will be my chance to shape whether those thoughts are good or bad. I told her not to talk to anyone about me. For now, it has to be our little secret. I think Lotus and I will share many secrets. Rose.

P.S.Ididn't notice until I had picked them up that the tiles were marked East and West. I gave the East one to Lotus, and kept theWest one formyself, of course. They will be an important part of our story together.

The diaries take advantage of the subtleties of contradictory stories. Readers must evaluate the entries and create inferences and draw conclusions about the characters of the two authors and the veracity of their statements in order to construct an idea of the truth. This is not given in the summaries which, for these first two entries, run as follows:

Week one: A strange young woman comes to a wedding. Her name is Rose and she meets another young woman 
"In software programming terms, these are called

Easter Eggs, the allusion being to the delight in hunting for them and the little reward that follows." named Lotus. Lotus is surprised when she learns that Rose is her cousin. There is an unusual gift, a mention of a diary box and a promise to see each other again. The mystery begins.

Within the diary entries, there are numerous hotword connections (underlined in the example above) that draw interested readers to information about Shakespeare, an illustrated copy of Charles and Mary Lamb's short story version of Romeo and Juliet, a description of the game Mah Jong, a map of Hong Kong showing the location described in the passage. There are also less obvious items such as share which leads to a summary and copy of Joseph Conrad's short story The Secret Sharer. Even more obscure are hidden hotwords, for example beneath the names of the two characters on the mastheads of the diaries. In software programming terms, these are called Easter Eggs, the allusion being to the delight in hunting for them and the little reward that follows. Clicking on Rose's masthead, for example, takes one to this entry:

Rose. There are many stories about the rose. One legend says that a young woman in Bethlehem was falsely accused and sentenced to death by burning. In a miracle, red and white roses appeared everywhere and she was saved. There is a language of flowers, with different roses having their own meanings:

Burgundy Rose... simplicity and beauty

China Rose... grace or beauty ever fresh

Daily Rose... a smile

Dog Rose... pleasure mixed with pain

Faded Rose... beauty is fleeting

Japan Rose... beauty your only attraction

Moss Rose... capricious beauty

Provence Rose... my heart is in flames

White Rose Bud... too young to love

White Rose Full of Buds... secrecy

Wreath of Roses... beauty and virture rewarded

Which rose would you like to receive?

At the base of each diary entry is a diary box; an elegant brocaded affair in Lotus' case and a tin box with a lock in Rose's. Clicking on these boxes takes one to a page which shows a cumulative collection of the various objects which the two young women place there each week. This idea of a diary box 
is further explained on a navigation button which sits beside the diary entries.

The diary box is explained as... a place for keeping memories. You can write something on a small piece of paper to go witheach one and wrap it up like a small present to yourself.

And suggestions for filling a diary box are given:

Here are some things that you might put into your diary box. admission tickets, airmail stickers, art exhibit brochures, autographs, bags from stores, balloons (deflated!), banana stickers, boarding passes, bookmarks, brochures, business cards, a butterfly wing, buttons, candy labels, cards from stores, cassette tape recording your favorite place, CD labels, chopsticks wrappers, drawings

and so on through the alphabet. A further note to encourage reader participation asks, If you have other ideas of things to include, click here and tell us.

For students wanting more information, under the Teach and Learn button is this entry:

For people who are learning English

For people who are teaching English
Lotus and Rose and their friends speak in English and explore Hong Kong. They keep diary boxes as a way of remembering what they have done. It's hard to keep a diary. People start writing then forget. They don't fill in a few days and then they think it's too late. But you can keep a diary box like Lotus and Rose. Click here for instructions. If you want to improve your English, think about doing some of the things Lotus and Rose do together. Also, look closely through the pages... some things are in blue writing, but there are also some hidden secrets. If you have any questions or comments about Lotus and Rose, please let us know: just click here.

One of the problems in constructing this virtual soap opera was deciding how to handle the teaching of idioms and grammatical items. It was initially planned that grammar notes would be included on the buttons but, after consideration, it was decided that the impression that the purpose of Lotus and Rose was more school work might take away from the enjoyable aspects of exploring the site. Instead, it was decided to create teaching and learning materials to be distributed to interested teachers in the form of a booklet of questions and discussion topics. Under the Teach and Learn button is the following entry:

People who are learning English in Hong Kong generally use textbooks that take all their examples from London or New York. The purpose of The Secret Diaries of Lotus and Rose is to encourage learners to look at local 
examples of language and local opportunities for language learning and hopefully see Hong Kong as a good place to learn English. Through 16 sets of diary entries, Lotus and Rose have several small adventures around Hong Kong. They do things, most of them free or inexpensive, which most students could easily do themselves.

You can encourage your students to look at Lotus and Rose each week. If you are a Hong Kong teacher, we can send you a free booklet on Teaching with The Secret Diaries of Lotus and Rose. Send us a message with your name and school address: just click here. The booklet gives suggestions for discussions and exercises on each lesson and tips on how to improve students' English. If you have any questions or comments about Lotus and Rose, please let us know: just click here.

The distribution of booklets will be further supported through posters, flyers and email messages advertising the site.

It can be seen through these brief examples that there are features which distinguish the WWW from both traditional language teaching practice and traditional media. Primary among these is the low cost of publication: nearly endless amounts of material can be included in hard drive storage, so the addition of further tangents with more learning resources, such as books as well as links to associated sites, is both easy and affordable. In traditional language practice, we assume a linear approach to the sequencing of vocabulary and grammar rules. But students show themselves able to learn vocabulary and grammar at various stages (see Nunan and Keobke 1997) and the spatial arrangement of information on the WWW means that students can navigate through those portions which are of greater interest and use to them while ignoring those portions which they already know.

Lynette Porter (1997) outlines nine other considerations in WWW-based learning:

- Potentially faster method of distribution

- Limited to learners with access to the Web

- May include hypertext and hypermedia materials

- May be accessed by many learners or a single learner at once

- May include email

- Involves more senses

- Can be updated frequently

- May require security to limit access to learners

- Limited instantaneous interaction between learners and educators/trainers (p. 39) 
Conclusion It is unlikely and undesirable that electronic media as described in the WWW soap opera outlined in this paper will, in the near future, replace paper textbooks; but as a supplementary resource for the encouragement and appreciation of language, it has great use for the inexpensive tailoring of individualized and localized materials. Teachers, school administrators and even learners are often polarized between high-tech and high-touch approaches to teaching and learning materials. There is no real need to side with one camp over the other; what is necessary is a clear-headed approach to materials evaluation that intelligently determines needs and examines the ability of materials to address those needs.

Appendix: Some Technical Aspects of Constructing a Serial Drama Web Site
In constructing a serial drama Web site, there are several issues in the administration of text, images and links. Lotus and Rose was constructed using Windows and Macintosh software, specifically, Word for Windows to write the original text and prepare it as .rtf files for use on a Macintosh Power PC. Images were either created by scanning in realia directly, laying them on top of a flatbed scanner, or taking photos and then digitally refining them in Adobe Photoshop. A digital camera would have simplified the task but was not budgeted for. Headlines and buttons were custom designed and created in Adobe Illustrator. The files were then constructed in Adobe PageMill, an intuitively constructed WWW authoring software which eliminates the need for learning HTML code. The availability of time and resources will govern whether it is possible to include sound, animation and video files but Hong Kong students' bandwid th and hardware limitations argue against it. The following are points which one might wish to consider:

- When using Macintosh software, it is best to use file names of eight letters or less, followed by a file format of threeletters, recognized by Windows-based systems. These files and the links were tested with a run-time version on a computer running Windows operating software and different browsers.

- Keeping within a standard 256-color palette will eliminate unsightly color shifts on computers not using millions of colors. For main titles, 16 colors are even better as they will appear the same on all computers, other than those with black-and-white monitors.

- The standard for screen resolution is 72 dots per inch (dpi). When scanning images in, using anything more 
than 72 dpi wastes hard-drive space and increases download time unnecessarily.

- It can be difficult to spellcheck and edit text once it is set into WWW pages. It is far better to completely edit text on a word processor before beginning WWW authoring. - As a rule of thumb, people can not distinguish more than about seven buttons on a screen. After seven buttons, they become lost.

- In creating links, it is necessary to consider how far one will go and how of ten one will want to return to a central place. Return buttons are necessary on each page and home buttons necessary on major pages.

- It is possible to install chat line or user postings facility into your homepage, but this may raise concerns of inappropriate messages being left.

- It is important to plan the duration of your site and label it as a static archive once you are no longer interested in maintaining it, removing unnecessary links that will not generate responses.

- Unix servers sometimes do not recognize uppercase letters in file names; use all lowercase to be safe.

Works Cited Bolter, J. D. Writing space: the computer, hypertext, and the history of writing. Hillsdale, New Jersey: Lawrence Associates, 1991.

Bruner, J. S. Toward a theory of instruction. Cambridge, MA: The Belknap Press of Harvard University Press, 1966.

Collins, R. The Spot, the book. New York: Fireside, 1996.

Lotus and Rose: http://www.cityu.edu.hk/ls/lotus\&rose.

Modelski, T. Loving with a Vengeance: mass-produced fantasies for women. New York: Routledge, 1990.

Mumford, L. S. Love and ideology in the afternoon: soap opera, women, and television genre. Bloomington: Indiana University Press., 1995.

Nunan, D. and K. Keobke. Growing Their Own Grammar: how learners can help themselves. Presentation to the Regional English Language Conference, May 1997

Porter, L. R. Creating the virtual classroom. New York: John Wiley \& Sons, 1997.

Reading and Writing the WWW: http://www.cityu.edu.hk/ls/ course/2640.

Stuart, R. Virtual reality: directions in research and development. Interactive Learning International, 8 (1992): 95100. 

The Secret Diaries of Lotus and Rose and Professors David Nunan, Amy Tsui and Christopher Candlin for discussions which, however tangential, continue to help shape my ideas on issues discussed in this paper. Funding to present this paper at the FLEAT III conference was provided by City University of Hong Kong.

Ken Keobke is a Lecturer at City University of Hong Kong and a Ph.D. Candidate with Professors David Nunan and Amy Tsui at the University of Hong Kong. He has taught in Canada, the People's Republic of China and Hong Kong. His publications include a primary listening series for Oxford University Press and a CD-ROM and World Wide Web site based on Mary Shelley's Frankenstein. 